\title{
LAS CANOAS DE JADE DEL SUR DE VERACRUZ COMO ELEMENTO ICONOGRÁFICO OLMECA PREVIO A LA ODISEA DEL DIOS DEL MAÍZ MAYA
}

\author{
Eric Orlando Cach Avendaño \\ Universidad de Guadalajara
}

Los olmecas, tradición civilizatoria preclásica, cuyo núcleo metropolitano se ha situado en los modernos estados mexicanos de Veracruz y Tabasco, forjaron una herencia cultural de innegable influencia en el mundo mesoamericano que sucedió a sus logros. Entre otros ejemplos se cuenta la escultura mayor, manejada por los olmecas con singular maestría, así como pequeñas esculturas de jade finamente trabajadas, que asombran por su calidad artística y perfección técnica. Este artículo hace referencia a un conjunto de obras poco conocidas que, a mi parecer, puede aportar pistas sobre un viejo sistema de creencias olmecas relativas a la creación del cosmos. Denomino "complejo" a dicho conjunto en tanto ofrece significados que trascienden su mera presencia física. Asimismo, trataré de argumentar que el "complejo de canoas de jade" representa parte de un mito olmeca que influyó en las ideas sobre la creación que tuvieron los mayas en épocas posteriores, concretamente en el mito del Dios del Maíz maya. Derivadas de este análisis, incluyo dos cuestiones, por un lado, una posible interpretación del ideograma asociado a una de las canoas de jade, por el otro, la representación del cosmos sugerida por las canoas.

El contexto histórico de las canoas de jade

Las esculturas de jade identificadas como canoas proceden del sur de Veracruz, distinguiéndose al menos cuatro de ellas; la más conocida fue recuperada arqueológicamente en Cerro de las Mesas y fechada en el Preclásico Medio (1 300 al 800 a.C.); una segunda pertenece a una colección particular en Campeche, y dos más se encuentran en museos del extranjero. ${ }^{1}$ Presumiblemente todas las

\footnotetext{
' La canoa de Cerro de las Mesas se encuentra en el Museo Nacional de Antropología e Historia; la segunda canoa, que motiva este trabajo, procede de Isla Piedra y está en una colección particular en la ciudad de Campeche; la tercera canoa se localiza en el Museum of Fine Arts de Boston y la cuarta está en The Brooklyn Museum, en Nueva York.
} 
canoas datan del mismo período. Las identificamos de acuerdo con su localización actual, en el siguiente orden: Canoa 1 (Museo Nacional de Antropología e Historia), Canoa 2 (Campeche), Canoa 3 (Boston) y Canoa 4 (Brooklyn). Las canoas 1 y 2 tienen motivos incisos, la 3 únicamente es la efigie de la canoa y la 4 tiene labrada en uno de sus extremos una especie de garra (figura 1). Exceptuando la Canoa 1, procedente de Cerro de las Mesas y ubicada en el Museo Nacional, las otras tres son producto de saqueo y desconocemos su contexto original, aunque podríamos suponer que provienen de ofrendas funerarias. Estas piezas son de diferentes tamaños, pero tienen una técnica similar de factura y guardan proporciones que evidencian un patrón de diseño. El jade empleado es de distintos tipos, por lo general de buena calidad. Tres de ellas tienen perforaciones, para ser utilizadas como pendientes.

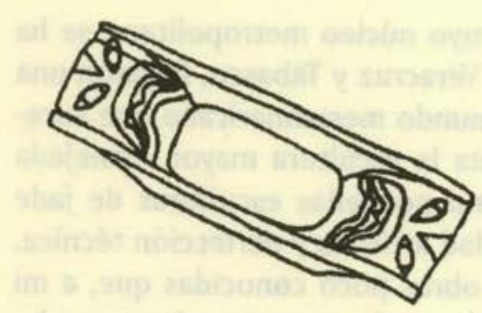

Canoa 1 (Museo Nacional de Historia)

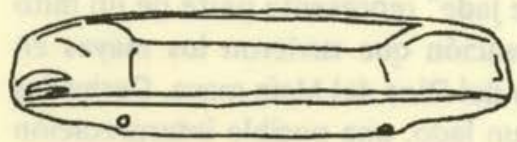

Canoa 3 (Museum of Fine Arts, Boston)

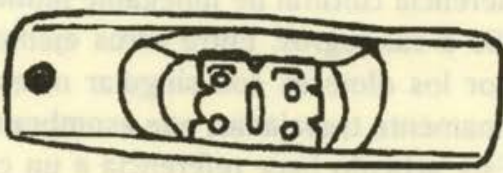

Canoa 2 (Colección particular, Ciudad de Campeche)

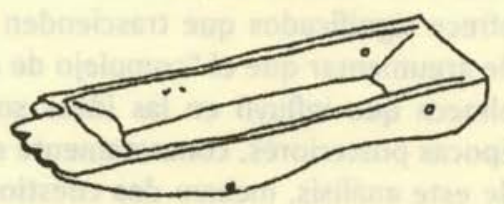

Canoa 4 (The Brooklyn Museum, Nueva York)

Figura 1. Canoas de Jade

Dibujos del autor, sin escala

De manera general, puede establecerse que durante la fase San Lorenzo, en la zona metropolitana olmeca se forma un entramado social que concibe el cosmos contenido, grosso modo, en un mito de creación en el que aparece un mundo dividido en dos planos, uno celeste-acuático y otro terrestre-subterráneo, de donde surgen los dioses como un complejo conformado al menos por ocho divinidades. ${ }^{2}$ Este mundo en dos planos es un espacio integrado por montañas y fuentes de agua sagradas, en el cual el agua es un elemento que funge como conexión entre ambos mundos. La existencia del hombre olmeca está asociada con un punto de equilibrio del cosmos, un motor que hace factible

\footnotetext{
${ }^{2}$ Joralemon, citado por Coe (1985: 74-77).
} 
la continuidad del quehacer divino e impide el cataclismo final. ${ }^{3}$ Esta ideología fue creación de una elite que para el 1400 a.C. tenía la suficiente fuerza y empuje para materializar estas creencias en objetos concretos de culto, que a su vez se convirtieron en símbolos de dominación, legitimidad y hegemonía dentro de un claro sistema de organización social jerarquizado y políticamente centralizado. De esta manera asistimos a la construcción de centros ceremoniales que reproducen los espacios sagrados de las montañas y las fuentes de agua, la factura de estelas con las imágenes de los dioses integrantes del panteón olmeca, y el depósito de masivas y espectaculares ofrendas que recrean el momento y el lugar de la creación primigenia. ${ }^{4}$ Es en este período cuando se realizan las obras de arte olmeca más espectaculares, tanto en escultura monumental como en el labrado de elaborados artefactos de jade. En la siguiente etapa, denominada fase La Venta, que inicia en el 800 a.C., se encuentran los primeros ideogramas asociados a estos objetos (por ejemplo, en las hachas de ofrendas de La Venta). ${ }^{5}$ Es difícil tener una certeza absoluta de esta aseveración, pero todo parece indicar que las representaciones de ideogramas olmecas ocurren en esta fase, con una serie de motivos que pueden dividirse en deidades, glifos, seres fantásticos, etcétera. Durante la fase de La Venta el mundo olmeca se entrega a un frenesí de fabricación de esculturas sagradas y al tráfico del jade, como materia prima y manufacturado para ofrendas. Es tal su intensidad que no tiene comparación con ningún otro momento de Mesoamérica; la explotación del jade es tan intensa que se agotaron las minas de este material o estuvieron cerca de hacerlo. En este período se realiza en Cerro de las Mesas una ofrenda masiva de más de 700 objetos de jade, excavada por Philip Drucker en los años cuarenta del siglo pasado, de la cual procede la canoa de 20 centímetros que aquí identificamos como Canoa 1 , recuperada en un contexto de reutilización.

\section{Los motivos incisos de las canoas 1 y 2}

La canoa de Cerro de las Mesas ha sido reproducida en varias publicaciones especializadas y de divulgación. Fue grabada en ambos extremos con una deidad bicéfala cuya característica sobresaliente es la abertura en " $v$ " de la frente; la representación de esta deidad no es inusual en la iconografía olmeca, sin embargo es bastante raro hallar su imagen bicéfala (Canoa 1 de la figura 1). Estos motivos incisos de los extremos de la canoa son la típica cara olmeca de ojos rasgados y boca "atigrada", con hendidura en "v" sobre la frente.

\footnotetext{
${ }^{3}$ Marcus (1985).

${ }^{4}$ Drucker (1952); Bernal (1968); Coe y Diehl (1980); Coe (1985); Lowe (1982, 1985); Piña Chan (1990).

${ }^{5}$ Lowe (1989: 52, figura 4.8).
} 


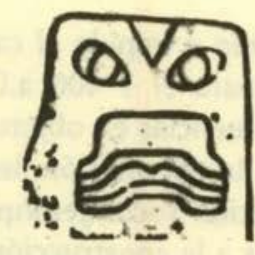

Figura 2. Motivo inciso en la canoa de Cerro de las Mesas

A los dioses olmecas con este tipo de hendidura se les identifica como una deidad del maíz, cuando surge de la hendidura una planta, aunque si falta la planta se asocian más bien con la deidad identificada por Joralemon como Dios IV, deidad que se supone es el antecedente directo del dios Itzamná. ${ }^{6} \mathrm{El}$ dios IV de Joralemon está de perfil, pero se distingue claramente la hendidura en " $v$ " acostada en su cabeza, tal y como aparece en diversas imágenes. ${ }^{7}$ En este caso, representado de frente y sin la planta del maíz, puede ser la deidad primigenia, el "Dios Primordial". ${ }^{8} \mathrm{Si}$ a ello agregamos que figura doblemente en la canoa y que ésta puede entenderse también — según Freidel, Schele y Parker- ${ }^{9}$ como una "canoa-cocodrilo", podríamos tener la representación de un ser fantástico, bicéfalo, de bocas atigradas y cuerpo de cocodrilo.

La canoa de Campeche es de menor tamaño (mide $7.8 \mathrm{~cm}$ de largo) y su materia prima es jade verde azulado; tiene un ideograma al centro de la pieza, el cual aparece en diversos monumentos y objetos procedentes de los más importantes sitios olmecas, como San Lorenzo, La Venta, Tonalá, Arroyo Pesquero y San José Mogote (Canoa 2 de la figura 1). Esta canoa tiene un signo inciso un tanto más misterioso, pero mucho más representado en el arte olmeca. El signo, grabado en el centro, está compuesto por un perímetro con cinco hendiduras $\mathrm{y}$ en el medio se hallan cuatro círculos dispuestos en un cuadro y una barra, además de una especie de cejas sobre cada uno de los círculos (figura 3).

Ahora bien, la interpretación de los esgrafiados de las canoas 1 y 2 debe hacerse sobre la base de que las canoas de jade son parte de un "complejo", del cual podemos deducir el significado. ${ }^{10}$ De esta manera, tenemos una canoa que representa un ser bicéfalo, que distingue a la canoa como "canoa-cocodrilo". La Canoa 2 y su ideograma de cuatro puntos y barra central requiere de mayor análisis para poder identificarla, por ello creo pertinente hacer una revisión más a fondo del signo.

\footnotetext{
${ }^{6}$ Citado por Coe (1989: 79).

${ }^{7}$ Esta deidad aparece en hachas votivas, esculturas y en un sello; véase Covarrubias (1942); Coe (1980); Soustelle (1984) y Piña Chan (1990).

${ }^{8}$ De hecho, Joralemon identifica a esta deidad como la más importante del panteón olmeca, el "dragón olmeca" o Dios I (Joralemon, 1976: 36-40).

${ }^{9}$ Freidel, Schele y Parker (1993: 87-94).

${ }^{10}$ Sólo analizaremos las canoas 1 y 2 , por ser las únicas con motivos incisos.
} 


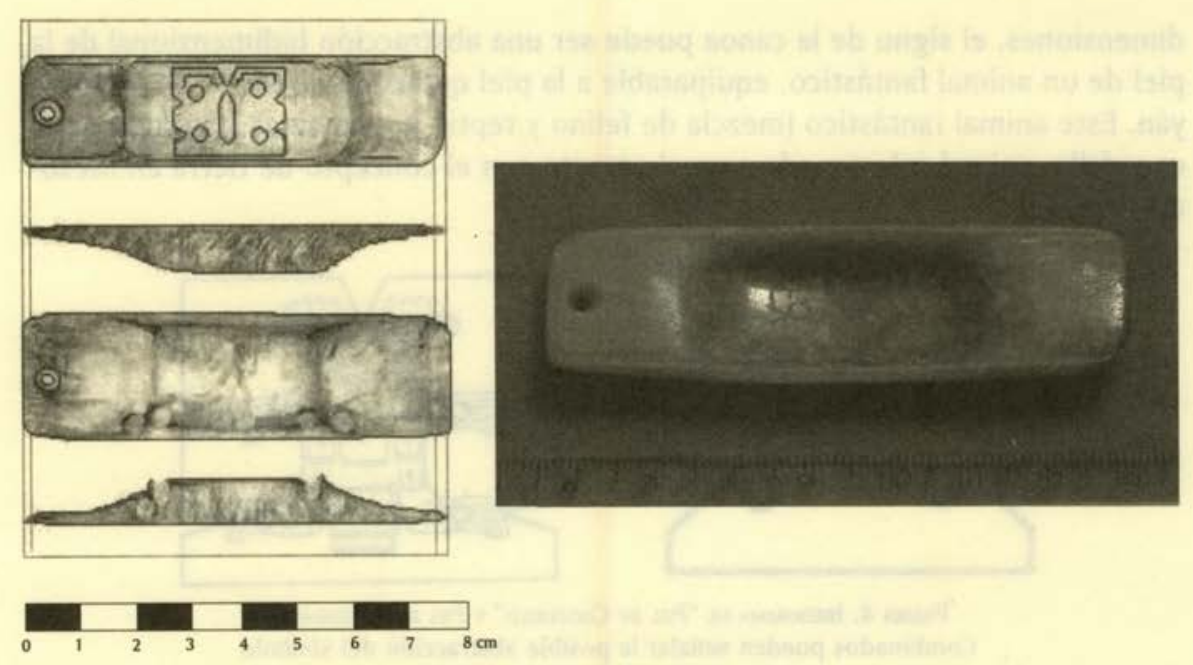

Figura 3. Motivo inciso en la canoa de isla Piedra, Campeche, y fotografía del. objeto Dibujo $\mathrm{y}$ foto del autor

\section{El ideograma "Piel de Cocodrilo" de la canoa de Isla Piedra}

El signo esgrafiado en el fondo de la Canoa 2 lo identifico tentativamente como "Piel de Cocodrilo", metáfora del concepto de "plano terrestre" o "lugar de la creación", indicando la posibilidad de un sitio sagrado. Es difícil, sin conocer el lenguaje de los creadores del ideograma, dar el significado preciso, pero creo que es posible aproximarse al concepto general que se intentaba expresar. De todos es conocido que en el mundo mesoamericano había una concepción cosmogónica que dividía al "mundo" en planos terrestres y celestes, dentro de un orden cuatripartita. ${ }^{11}$ Por ello, es relevante señalar que los cuatro puntos del ideograma en cuestión podrían indicar rumbos cardinales o "esquinas del mundo", y la barra representar un quinto elemento o "centro". ${ }^{12}$ Hay que mencionar también la hendidura en " $\mathrm{v}$ " de la parte superior, la cual puede fungir como marcador de un rumbo cardinal, además de estar relacionada con las otras cuatro hendiduras laterales del ideograma. ${ }^{13}$ Considerando la sugerencia de Graham y Benson ${ }^{14}$ de que el arte olmeca es esencialmente un arte glífico de tres

\footnotetext{
11 Véanse, por ejemplo, Florescano (1994) o López Austin (1984).

${ }^{12}$ Podría ser relevante recordar que el signo para el numeral 5 entre los mayas es precisamente una barra.

${ }^{13}$ Joralemon identifica un motivo que llama "el símbolo de cuatro puntos y barra" (1976: 47) que es parte del que aquí identificamos como "piel de cocodrilo". La diferencia fundamental es que aquí se trata de los cuatro puntos y la barra más el perímetro de las cinco hendiduras.

${ }^{14}$ Graham (1990: 77-84).
} 
dimensiones, el signo de la canoa puede ser una abstracción bidimensional de la piel de un animal fantástico, equiparable a la piel que cubre al señor de Atlilhuayán. Este animal fantástico (mezcla de felino y reptil) puede estar inspirado en el cocodrilo, animal relacionado estrechamente con el concepto de tierra en Mesoamérica.
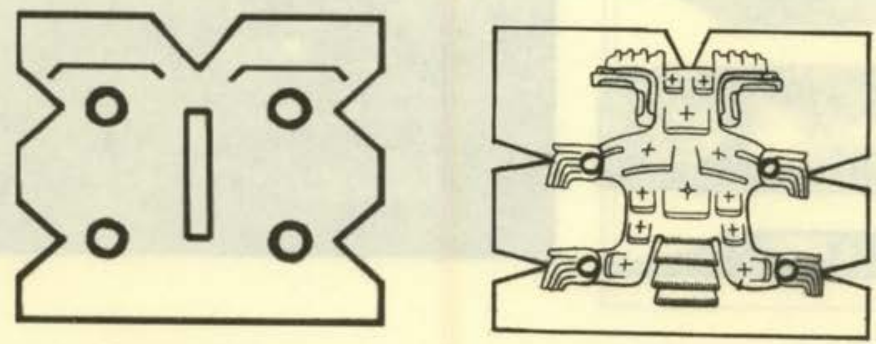

Figura 4. Ideograma de "Piel. de Cocodrilo" y Piel de Atulhuayán Combinados pueden señalar la posible abstracción del símbolo Modificado de Piña Chan, 1990

Partiendo de esta idea podemos ver las representaciones de este ideograma en los mosaicos subterráneos de serpentina de La Venta (figura 6, dibujos c, d, y e) como símbolos de este "lugar de creación"; también de La Venta son las hachas votivas con este signo en la parte central, de donde emerge una planta (figura 6, dibujos $\mathrm{g}$ y h), lo cual refuerza la idea de que se trata de un elemento terrestre. Si bien Marcus hace la lectura de "tierra" para un símbolo muy similar en San José Mogote (figura 6, dibujo h), me parece más adecuado definir este ideograma como un elemento terrestre, debido a que hay que agregar a la posible identificación del signo como piel de cocodrilo (metáfora del plano terrestre), un elemento de acción. Es decir, este lugar, la piel del cocodrilo, no es cualquier "tierra", es el lugar de la creación. Aunque he optado por el término "cocodrilo" como complemento que determina la expresión "Piel de...", podría ser que en la fórmula original el sustantivo se refiera a ese ser fantástico al que ya he aludido, y que no es otro más que el monstruo terrestre, mezcla de diversos animales. ${ }^{15}$ Sobre su lomo están situadas las esquinas del mundo y en el centro, una barra o poste que por el hecho de ser erigido se constituye en un acto de creación. El momento de erigir el poste o axis mundi lo vemos representado en esculturas olmecas como la del Príncipe, de San Martín Pajapan; joven sacerdote olmeca con atributos del ser felino en posición de levantar una barra. En consecuencia, la representación isométrica del ideograma "Piel de Cocodrilo" se aprecia como un plano terrestre sobre el cual están señaladas las esquinas del mundo, con un poste central en espera de ser levantado (figura 5).

${ }^{15}$ Por economía del lenguaje, he optado por identificar el glifo como "Piel de Cocodrilo", sin embargo muy probablemente la "piel" pertenezca a un animal fantástico cuya denominación se des- 


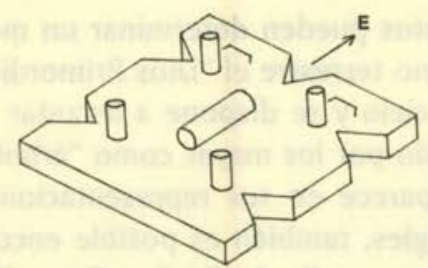

Figura 5. Isométrico del ideograma "Piel de Cocodrilo" Dibujo del autor

A este signo, significante de una piel de cocodrilo o de un ser con atributos de cocodrilo, cuyo significado muy probablemente sea "plano terrestre" o "lugar de la creación", habría que agregarle la identificación que hace Joralemon (citado por Coe, 1989) de la hendidura asociada a una planta como elemento del Dios II, divinidad del maíz, por lo que podemos inferir que el ideograma "Piel de Cocodrilo" es un signo asociado a esta deidad. ${ }^{16}$ En una estatua procedente de Arroyo Pesquero se aprecia sobre la cabeza del sacerdote un tocado representando un dios con la hendidura en " $\mathrm{v}$ " y cuatro pétalos abajo, enmarcado por una planta trilobulada, lo cual refuerza la asociación del signo "Piel de Cocodrilo" con una deidad del maíz (figura 6 , dibujo b). Tenemos entonces que,

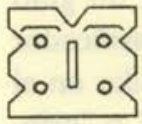

A

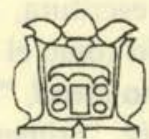

B

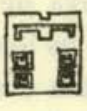

C

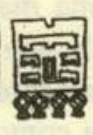

D

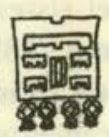

$\mathrm{E}$

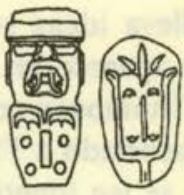

F G

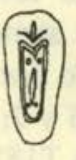

$\mathrm{H}$
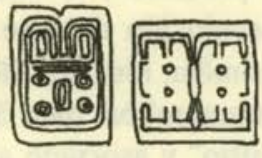

J

A. Glifo en la canoa de jade procedente de Isla Piedra, Campeche

B. Glifo en la parte superior de una estatuilla procedente de Arroyo Pesquero, Veracruz

C, D y E. Mosaicos subterráneos localizados en La Venta, Tabasco

F. Hacha votiva, con ser felino, de La Venta, Tabasco

G y H. Hachas de ofrenda, con plantas surgiendo del glifo "Piel-cocodrilo", La Venta, Tabasco

1. Glifo en un sello procedente de Tlatilco

J. Glifo de San Jossé Mogote, identificado como "tierra" por Marcus

Figura 6. El ideograma "Piel de Cocodrilo" en diversos artefactos olmecas Dibujos del autor

conoce. Quizás el sustantivo en la frase aluda a un ser "felino-reptil", o contenga atributos de otros animales.

${ }^{16}$ Joralemon asocia el motivo de cuatro puntos y barra a un emblema del Dios I, "El Dragón Olmeca" (1976: 47); aquí se trata de un glifo ("piel de cocodrilo") que incorpora este motivo a un perímetro con cinco hendiduras, el cual considero asociado al Dios Il o del Maíz. 
combinados, estos elementos pueden determinar un momento específico de la creación: cuando en el plano terrestre el "Dios Primordial" ha erigido los cuatro postes que sostendrán el cielo y se dispone a levantar el último poste central, el más importante, conocido por los mayas como "árbol celeste" o Wakah Chan. $\mathrm{Si}$ bien este ideograma aparece en sus representaciones tempranas en forma individual y asociado a efigies, también es posible encontrarlo relacionado con otros glifos, por ejemplo, en un sello de Tlatilco (figura 7). Hay tres glifos en este sello, vistos de izquierda a derecha el primero es identificado por Maricela Ayala como "el cielo"; ${ }^{17}$ el segundo representa una deidad con una hendidura del que emerge una planta (Dios II o del Maíz de Joralemon), y el último signo es el ideograma "Piel de Cocodrilo". En sus tres componentes básicos podemos entresacar la fórmula Tierra-Deidad-Cielo, pero una lectura rudimentaria podría ser "La tierra celeste del Dios Maíz" o "La tierra celeste del Dios Creador". Pero si el ideograma "Piel de Cocodrilo" implica una acción (el acto de crear), la posible lectura sería "El cielo donde el Dios Maíz realizó la creación" o "El cielo del Dios Maíz, lugar de la creación".

Como ya mencionamos, Marcus lee este signo como "tierra" y lo asocia a una división social de la localidad en dos grupos de ascendencia patrilateral, cada grupo relacionado con un culto distinto a las serpientes-rayo o los jaguares-tierra; ${ }^{18}$ también es interpretado por Alfonso Caso como "turquesa". La turquesa o el jade, en sus acepciones básicas, se interpretan como materializaciones de lo "precioso", lo cual conlleva ideas sobre lo sagrado o lo divino. Una posible evolución de este signo aparece en el sistema maya de escritura, en un glifo similar, identificado por Thompson como T585, que es leído como el clasificador numeral bix para 5 y 7; asociado a T168 se interpreta como bixnel, "bailar en el sitio" y asociado a T181 se lee fonéticamente como ha nabe, "primero" o "príncipe". ${ }^{19}$ La frase "bailar en el sitio" debería hacernos reflexionar en que "sitio" puede referirse a un sitio sagrado, quizás el de la creación, y "primero", a un actor sagrado, un creador.

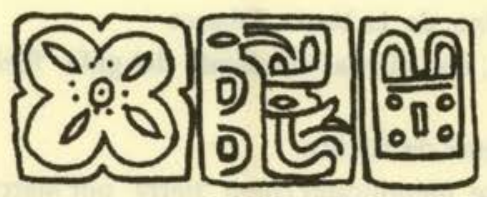

Figura 7. Dibujo esquemático del sello de Tlatilco publicado por Soustelle (1984)

\footnotetext{
${ }^{17}$ Ayala (1983).

${ }^{18}$ Marcus (1985: 168-170).

${ }^{19}$ Ayala (1983).
} 
En otro nivel, las canoas de jade pueden ser entendidas como parte de un conjunto semántico, del cual pueden inferirse otros significados. Si hemos podido determinar que las canoas 1 y 2 contienen ideogramas con mensajes específicos, no podemos separar estos ideogramas del objeto en sí y su materia prima, como parte de un sentido de significación mayor. El jade era valioso para los olmecas porque materializaba el sentido de lo "precioso", lo "vital". Y las canoas son en sí un vehículo de transporte acuático, un transporte divino en un plano de existencia diferente al terrenal. Es posible que estos artefactos estén relacionados con el mito de creación del cosmos olmeca, en el cual las canoas fungieron como vehículos de un dios primordial por los planos celestes de la creación; al agregar a las canoas los ideogramas del dios bicéfalo (dios primordial en la Canoa 1) y de "Piel de Cocodrilo" (lugar de creación en la Canoa 2), se concibe a las canoas como representación ideal de los planos celestes.

Lo anterior nos da pistas sobre la concepción del espacio que tenían los olmecas, pues si representan planos del espacio como el cielo y la tierra, muy probablemente indiquen algo sobre su orientación. Aceptando la idea de que la divinidad bicéfala celeste es una representación de la Vía Láctea en posición este-oeste, es de suponer que la canoa de Cerro de las Mesas tiene esa misma orientación. Ahora bien, la canoa de Isla Piedra con el ideograma de "Piel de Cocodrilo" en su centro tiene una hendidura en " $v$ ", que seguramente señala el este..$^{20} \mathrm{Al}$ sobreponer ambas canoas, colocando las hendiduras de los ideogramas hacia el este, y asumiendo que la Canoa $1 \mathrm{y}$ las hendiduras de la deidad bicéfala se orientan a ese rumbo, resulta que la Canoa 2 orienta sus extremos en sentido norte-sur, de tal manera que las canoas integran una cruz (figura 8). Sobreponiendo ambos planos y orientándolos en planos cuadrados, obtuve un diseño en el que incluí los puntos cardinales e intercardinales, tal como los identificaron los mayas, ${ }^{21}$ con sus glifos respectivos; además de los nombres de los chakes que presiden cada cardinal, y ubiqué a los batabes como cargadores en los cuadros intermedios. Considerando la orientación al este del signo "Piel de Cocodrilo" en la Canoa 2, asumí que el eje de la canoa es norte-sur, lo cual indica que la canoa va en dirección norte, exactamente a la región donde se hizo la casa de las ocho divisiones al terminarse la creación del mito maya (figura 9). Esta disposición recuerda las concepciones del mundo que tienen los mayas de Quintana Roo y Yucatán, según Villa Rojas, ${ }^{22}$ así como la de los tzotziles de Chiapas,

${ }^{20}$ Es necesario remarcar lo que muchos epigrafistas, historiadores y arqueólogos han señalado: si bien el rumbo norte es un verdadero referente geográfico, para los mesoamericanos muy probablemente el este fuese el rumbo más importante.

${ }^{21}$ Existe una identificación glífica de los rumbos cardinales e intercardinales de los mayas que hace David Stuart de la Tumba de Río Azul (citado por Freidel, Schele y Parker: 72, figura 2.8).

${ }^{22}$ Villa Rojas (1985: 313-336). 
según los reportes de Ochiai. ${ }^{23}$ El diseño de esta concepción recuerda en general la disposición de las láminas 75 y 76 del Códice Madrid, así como el signo de rueda dentada del monumento 46 de San Lorenzo Tenochtitlán. ${ }^{24}$

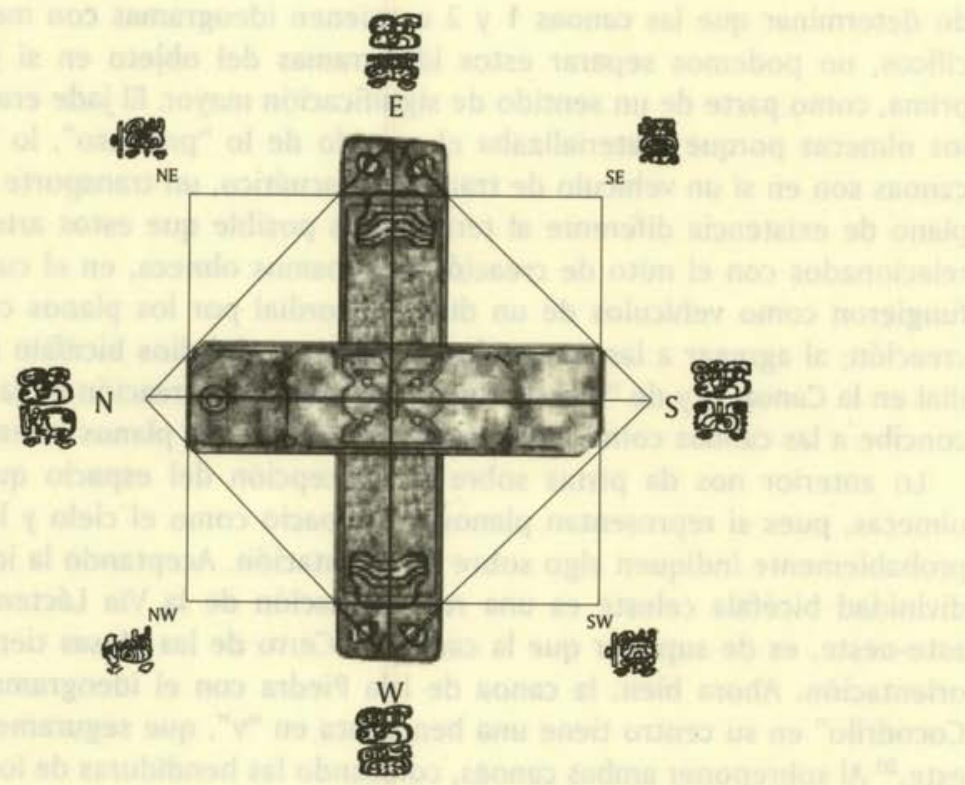

Figura 8. Las canoas como planos celestes

Se sobreponen los glifos indicadores de los rumbos cardinales e intercardinales Dibujo del autor

Por tanto, el complejo de canoas de jade es un complejo de canoas celestes, las cuales constituyen en sí mismas elementos iconográficos que representan los planos de la creación. Es importante recordar la asociación que se hace del Dios IV con Itzamná y del Dios II con Hun Nal Ye, pues de acuerdo con Barrera Vázquez (1995) existe una expresión en maya para designar a un ser fantástico, el Itzam kab'ain, traducido como el Itzam cocodrilo-tierra, entendiendo a itzam como "brujo o mago del agua". Pero más interesante aún es cuando este apelativo se contrapone con otro que designa a seres anfibios y celestes: Itzamná, término no sólo para nombrar a esta deidad maya, sino también con el significado de cielococodrilo. Por analogía, podemos determinar entonces que la canoa de Cerro de las Mesas en realidad representa un cocodrilo bicéfalo, un "Cielo cocodrilocelestial", mientras que la canoa de Isla Piedra, con un signo asociado al Dios del Maíz, puede estar representando un "Cielo cocodrilo-terrenal".

\footnotetext{
${ }^{23}$ Ochiai (1985: 43-66).

${ }^{24}$ Coe (1980: 355, figura 486).
} 


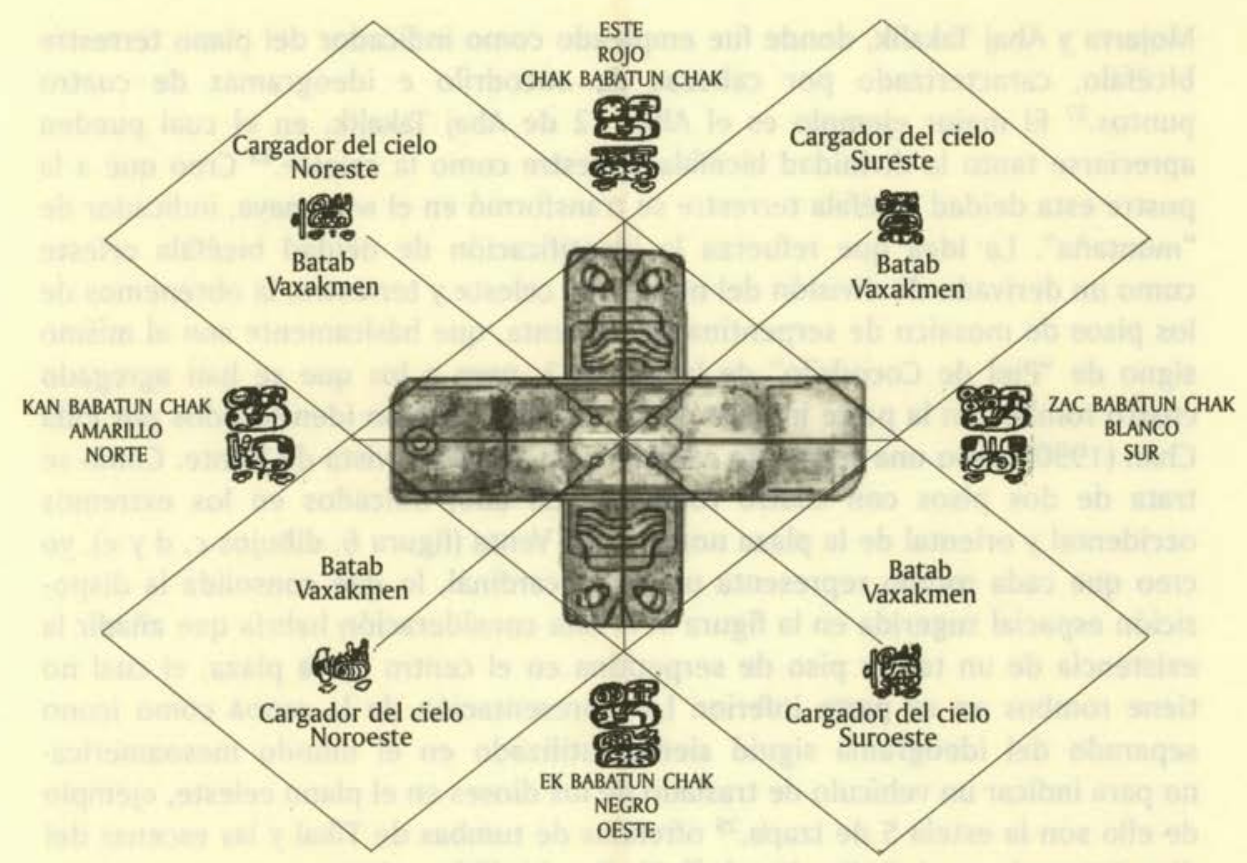

Figura 9. Las canoas 1 y 2 con los puntos cardinales e intercardinales, en un cosmos de ocho posiciones Se ubican los Chakes que presiden cada punto cardinal. En los cuadros marcados como "cargadores del cielo" se colocaron los glifos mayas de los intercardinales y se agregaron los términos en yucateco y tzotzil que indican tal figura. La identificación de los chakes con un determinado rumbo y color se tomó de Villa Rojas, y el término batab de Landa. El vocablo vaxakmen es de Ochiai, en su capítulo sobre el cosmos tzotzil

Dibujo del autor

La canoa de Cerro de las Mesas, como representación de un ser bicéfalo, sería análoga a los bastones dobles que abrazan ciertas deidades mayas, y que, de acuerdo con el razonamiento de Freidel, Schele y Parker, representa la Vía Láctea. Posteriormente en el mundo maya ésta sería la deidad bicéfala celeste representada en diversos monumentos del Clásico, como puede apreciarse en estelas de Yaxchilán, Lacanhá y Palenque. ${ }^{25}$ La canoa de Isla Piedra representaría, por oposición a la de Cerro de las Mesas, el plano terrestre, "el lugar". El ideograma que se le asocia, denominado aquí "Piel de Cocodrilo", fue usado copiosamente en monumentos, ofrendas de hachas y pisos de serpentina del período La Venta, ${ }^{26}$ por lo que puede asumirse con seguridad que fue ampliamente utilizado entre los años 800 al 200 a.C. A su vez, el significado del ideograma (que no el significante) se utilizó en las estelas de Tres Zapotes, Ángel R. Cabada, La

\footnotetext{
${ }^{25}$ Véanse Soustelle (1983), Piña Chan (1990) y Ruz Lhuillier (1992).

${ }^{26}$ Puede resultar interesante recordar que Joralemon (1976: 47) encuentra 24 representaciones del motivo de "cuatro puntos y barra" en 80 obras olmecas de La Venta y Arroyo Pesquero.
} 
Mojarra y Abaj Takalik, donde fue empleado como indicador del plano terrestre bicéfalo, caracterizado por cabezas de cocodrilo e ideogramas de cuatro puntos. ${ }^{27}$ El mejor ejemplo es el Altar 12 de Abaj Takalik, en el cual pueden apreciarse tanto la divinidad bicéfala terrestre como la celeste. ${ }^{28}$ Creo que a la postre esta deidad bicéfala terrestre se transformó en el witz maya, indicador de "montaña". La idea que refuerza la identificación de deidad bicéfala celeste como un derivado de división del mundo en celeste y terrestre, la obtenemos de los pisos de mosaico de serpentina de La Venta, que básicamente son el mismo signo de "Piel de Cocodrilo" de la Canoa 2, pero a los que se han agregado cuatro rombos en la parte inferior. Estos mosaicos fueron identificados por Piña Chan (1990) como una serpiente estilizada de cascabel, vista de frente. Como se trata de dos pisos con cuatro rombos cada uno, ubicados en los extremos occidental y oriental de la plaza norte de La Venta (figura 6 , dibujos c, $d$ y e), yo creo que cada rombo representa un plano cardinal, lo que consolida la disposición espacial sugerida en la figura 9. A esta consideración habría que añadir la existencia de un tercer piso de serpentina en el centro de la plaza, el cual no tiene rombos en su parte inferior. La representación de la canoa como icono separado del ideograma siguió siendo utilizado en el mundo mesoamericano para indicar un vehículo de traslado de los dioses en el plano celeste, ejemplo de ello son la estela 5 de Izapa, ${ }^{29}$ ofrendas de tumbas de Tikal y las escenas del dios Itzamná en el Códice Dresde. ${ }^{30} \mathrm{El}$ dios bicéfalo celeste no aparece representado con tanta frecuencia como el ideograma "Piel de Cocodrilo", pero posteriormente los mayas al parecer lo retoman como divinidad principalísima.

\section{La creación olmeca y la creación de Hun Nal Yeh}

En fechas muy tempranas el mito de creación olmeca involucró un conjunto de elementos utilizados en complicados rituales que reproducían el momento primigenio. Por ejemplo, ofrendas de hachas, bustos, arcillas de colores, pelotas de hule y, muy posible, sacrificios con sangre humana. Posteriormente se recreó el panteón con esculturas de piedra, que representaban dioses y gobernantes divinizados o en contacto con los dioses; pero en el extremo de esta ritualización, los olmecas no se conformaron con fabricar dioses, sino que reprodujeron las condiciones mismas de la creación original. De esta manera, los espacios arquitectónicos de San Lorenzo y La Venta reproducen los espacios sagrados; si consideramos que la creación final del mundo conocido por los olmecas ocurre cuando se "eleva" el cielo en la región norte, podemos aventurar una hipótesis

\footnotetext{
27 Véase la parte inferior de las estelas de Ángel R. Cabada (Covarrubias, 1961); La Mojarra (Winfield, 1988) y de Bilbao (Piña Chan, 1990).

${ }^{28}$ Graham (1990).

29 Lowe (1982).

${ }^{30}$ Universidad Autónoma de Chiapas (1985).
} 
explicativa de por qué los olmecas orientaban sus edificios en un eje norte-sur: estaban situando su civilización en el momento mismo de la creación. Es en la fase intermedia de los olmecas, conocida como fase La Venta, cuando se empiezan a utilizar ideogramas de dioses y de sus atributos divinos - Joralemon identifica al menos ocho de estos dioses-. Para el caso que aquí nos ocupa podemos establecer un complejo de ideogramas que incluye a los dioses II y IV de Joralemon, ${ }^{31}$ las canoas de jade, las ofrendas de hachas de toda el área olmeca y las ofrendas de bustos de madera de Manatí. Este complejo representa el mito de creación olmeca, reproducido con sus propias características por los mayas del Clásico. Los ideogramas de este mito son, desde luego, el signo "Piel de Cocodrilo" y la divinidad bicéfala celeste o "Dios Primordial".

Al parecer, este culto se transforma en el período Postolmeca, tal como aparece en las estelas de La Mojarra, Abaj Takalik y Angel R. Cabada, donde la divinidad del plano terrestre piel-cocodrilo se transforma en una deidad bicéfala, al igual que su contraparte celeste. Quizá para el mundo clásico maya se transmutó en Witz, la montaña sobre la que a veces aparecen representados los señores mayas, pero lo cierto es que en esa época prevalece la deidad bicéfala celeste.

Con las reservas del caso, hago uso de la hipótesis de continuidad en las tradiciones culturales olmecas que trascendieron a los mayas del Clásico e incluso a tradiciones mexicas del Postclásico, en tanto conservaron las ideas primigenias del cosmos creado por las elites olmecas. Pero aquí emplearé una fuente que hace algunos años hubiera sido insospechada: la saga del joven Dios del Maíz maya, leída e interpretada de monumentos y cerámicas mayas del Clásico (véase Freidel, Schele y Parker, 1993; Quenon y Le Fort, 1997). La razón de partir del mito de creación de Hun Nal Yeh, Dios del Maíz, estriba en que la revisión iconográfica de las representaciones de canoas en el arte maya, izapeño y olmeca tiene ejemplos que van desde las mismas canoas de jade (fechadas entre el 1200 y 800 a.C.) hasta las pictografias del Códice Dresde, hacia el 1250 d.C.

El mito de creación de los mayas parece contener elementos del mito de creación olmeca, por lo cual trataremos de inferir algunas cuestiones de la revisión de los textos de la Estela "C" de Quiriguá, el Tablero de la Cruz en Palenque, la cerámica de ofrendas de Tikal y los huesos esgrafiados de la tumba 116 del mismo lugar. Estas fuentes del Clásico maya se sitúan en un período que va del 700 al 850 d.C., y narran la saga de la creación del Dios Joven del Maíz, con un papel protagónico. La relación que existe entre este mito y las canoas de jade olmecas se encuentra en un pasaje principal, cuando el Dios Jaguar y el Dios Mantarraya trasladan al Dios del Maíz al lugar de la creación a bordo de una canoa; en otro momento el mismo Itzamná es el remero de la canoa. En una

\footnotetext{
${ }^{31}$ Joralemon identifica tres pares de dioses olmecas relacionados iconográficamente entre sí, el primer par son los dioses I y III; el segundo es el de los dioses II y IV, y el último par son los dioses VI y VIII (1976: 33).
} 
versión libre de la lectura que Freidel, Schele y Parker hacen de la estela " $C$ " de Quiriguá podemos leer el siguiente relato de la creación:

En 4 ahau 8 cumkú fue la creación, el Dios Jaguar y el Dios Mantarraya, colocaron y plantaron tres piedras en Na Ho Chan, Trono de Piedra Jaguar; Ek Na Chak plantó otra piedra en Kab (Lugar de la Tierra) Trono de Piedra Serpiente; y entonces sucedió que Na Itzamhi plantó otra piedra, el Trono de Piedra Nenúfar. Todo esto sucedió en Ch'a Chan, Lugar de las Tres primeras Piedras. Han transcurrido 13 baktunes desde ese suceso. Señor Wak Chan. ${ }^{32}$

En este texto básicamente se narra la forma en que cuatro deidades, una de las cuales (Ek Na Chak) es presumiblemente el Dios del Maíz, participan en la creación al colocar tres piedras, que son denominadas como "tronos" con nombre propio, en una fecha determinada. En el texto de la creación del Tablero de la Cruz en Palenque, a pesar de algunos pasajes oscuros, el mito de la creación más o menos puede leerse de la siguiente forma:

Han transcurrido 5 uinales y 8 tunes desde 12.19.13.4.0. 8 ahau 18 zec, después de nacer él ocurrió un hecho en 4 ahau 8 cumkú, se completaron 13 baktunes; 1 tun, 9 uinales y 2 kines después Hun Nal Yeh entró en el cielo. En 13 lk asiento de mol fue barrido el Wakah Chan y se hicieron ocho divisiones a la Casa del Norte. Transcurrieron 12 uinales, 3 tunes, 18 katunes y un baktún y fue roto el corazón de Wakah Chan, Hun Nal Yeh llegó entonces a Matawil. ${ }^{33}$

Lo relevante en este texto es que Hun Nal Yeh entra en el "cielo", que puede ser interpretado como un evento astronómico o un renacimiento, y respecto a la edificación de una casa de ocho divisiones en una región norte, se entiende como la "elevación" del cielo, la erección del Wakah Chan, el árbol celeste. Otro episodio de esta saga ocurre en el Vaso de los Siete Dioses, ${ }^{34}$ donde se ilustra que la creación acontece en 4 ahau 8 cumkú, cuando se puso en orden el lugar llamado Ek'u tan (negro es su centro), ordenándose los dioses por jerarquías, primero Dios Cielo, luego Dios Tierra, Dios Nueve Pasos, Dios Tres Nacidos Juntos, Dios Ha Te Chi y el Remero Jaguar. De esta escena yo destacaría que sobre la imagen sedente del Dios L hay una figura de cocodrilo, el cual bien podría representar algo celeste o el cielo mismo. En otras imágenes de vasos de Tikal, se aprecia cómo en un mundo acuático, el Dios del Maíz es vestido por una joven desnuda para ser llevado al lugar de la creación por los remeros divinos, y después renacer de un monstruo pez-serpiente ${ }^{35}$ en el Inframundo. ${ }^{36}$ En otro acto de renacimiento del Dios del Maíz éste surge del caparazón roto de

\footnotetext{
${ }^{32}$ Freidel, Schele y Parker (1993: 67, figura 2.5).

${ }^{33}$ Ibid., pp. 64-68.

${ }^{34} \mathrm{Ibid}$., p. 68 , figura 2.6 .

${ }^{35}$ De acuerdo con la identificación de Quenon y Le Fort (1997: 888-889).

${ }^{36}$ Freidel, Schele y Parker (1993: capítulo II).
} 
una tortuga. De las imágenes de los huesos ofrendados en la tumba del señor Ka'an K'awil, puede distinguirse que el Dios del Maíz es trasladado junto con una iguana, un mono, un loro y un perro al lugar de la creación por el Remero Mantarraya y el Remero Jaguar; ${ }^{37}$ en otro hueso la canoa y sus tripulantes se hunden; en otra escena la canoa, con proa de cocodrilo, es conducida por un remero insospechado: Itzamná.

David H. Kelly, en su libro Deciphering the Maya Script (1976) menciona que en esos huesos de Tikal, luego del nombre del gobernante, aparecen los glifos del Dios K (del maíz) y de "cielo" (p. 231), lo cual puede ser una cláusula semejante a la del sello de Tlatilco que presentamos en la figura 7. El investigador considera que los textos tienen carácter histórico, aunque las imágenes son de fuerte contenido mitológico. Los animales que acompañan al dios en la canoa, sostiene, son análogos a los animales mencionados en el Popol Vuh y los Anales de los cakchiqueles, los cuales obtuvieron maíz para la creación de la humanidad, y refiere que Paxil, el lugar donde obtuvieron el maíz, es un término que significa "inundación". Kelly encuentra una conexión entre estos personajes en la canoa y la creación de la humanidad. Asimismo, considera que estas imágenes, por estar acompañadas de un texto histórico, podrían referirse a un nacimiento, quizá el del gobernante maya mencionado (pp. 236-237).

Aunque para entender mejor la secuencia de los hechos es necesario remitirse al trabajo de Michael Quenon y Geneviève Le Fort (1997), denominado "Renacimiento y resurrección en la iconografía del Dios del Maíz", ${ }^{38}$ relativo a la interpretación iconográfica de los eventos relacionados con el Dios del Maíz maya del Clásico. En este estudio identifican diversos elementos de la iconografía asociada al Dios del Maíz, y los distintos episodios de la saga de este dios; uno de éstos es el traslado del Dios del Maíz en una canoa a un lugar específico. Los autores señalan que las estelas clásicas mayas generalmente retratan gobernantes y algunas de ellas los representan vestidos con los ropajes propios del Dios del Maíz, básicamente una falda en red con cuentas y un cinturón con una concha Xoc (Spondylus), insertada en el centro (p. 884).

Quenon y Le Fort aseguran que la mitología del Dios del Maíz, de acuerdo con la interpretación de Freidel, Schele y Parker, ${ }^{39}$ consta de una serie de metáforas sobre la creación del mundo y su constante renovación; pero su interés se centra en el vínculo que existe entre el ropaje del Dios del Maíz y el relato épico, más que en las implicaciones cosmogónicas. Es importante resaltar que la figura de "Dios Maíz" de la que parten se refiere a las formas sobrepuestas y desarrolladas a lo largo de la época de dicha deidad, y no a una forma única e invariable. También relacionan al Dios del Maíz del período Clásico, llamado Hun

\footnotetext{
${ }^{37}$ Loc. cit.

${ }^{38}$ El texto en inglés se titula "Rebirth and resurrection in maize god iconography", en The Maya Vase Book, vol. 5, Kerr Associates, 1997.

${ }^{39}$ Citado por Quenon y Le Fort (1997: 884).
} 
Nal Yeh (Uno-Maíz-Revelado) con Hun Hunahpú, padre de los héroes gemelos en el relato del Popol Vuh, y señalan que las representaciones de mujeres ataviadas como Dios del Maíz pueden ser personificaciones de la diosa lunar, lo cual remite a lo establecido por Schele ${ }^{40}$ respecto a que ambos son representaciones del primer padre y la primera madre de los dioses.

Los autores identifican cuatro episodios en secuencia de la mitología del Dios del Maíz, entresacados de representaciones individuales en cerámicas mayas del Clásico. Estas escenas son: el renacimiento del dios, el acto de vestirlo, el suceso de la canoa, y la resurrección. ${ }^{41}$ El primer episodio, el renacimiento del dios, se interpreta a partir de escenas de la cerámica en donde éste emerge de una serpiente, ${ }^{42}$ dentro de un mundo acuático, desnudo y con apenas un tocado y pulseras. Pero esta serpiente la consideran como una entidad diferente de la identificada por Schele como "Visión Serpiente", y encuentran elementos iconográficos suficientes para distinguir a este ser como un monstruo Pez-Serpiente, que caracterizan como Xoc, además de estimar al pejelagarto (Lepisosteus tristoechus) como un buen candidato para ser la inspiración de tal deidad. De hecho, establecen una relación entre la representación olmeca de un pez zoomorfo grabado en serpentina y dicho pez (pp. 886-890).

Quenon y Le Fort anotan que en los huesos incisos del entierro 116 de Tikal pueden apreciarse dos momentos del relato del Dios del Maíz, su descenso como dios muerto en una canoa al submundo acuático, y su posterior regreso y resurrección (p. 891). Las escenas del renacimiento, repetitivas en la cerámica maya, les sugieren que este episodio es un tema mitológico por sí mismo, y la razón por la cual el dios emerge de un pez, suponen, puede deberse a que algunos mitos arcaicos mesoamericanos ubican la creación de los seres humanos a partir de hombres-peces y el robo del maíz de una montaña, lo que implica cierta analogía entre pez y maíz (idem).

El segundo episodio, el acto de vestir al dios, básicamente consiste en que éste, recién surgido del monstruo pez-serpiente y semidesnudo, es ayudado a vestirse por dos o más mujeres. Uno de los accesorios que le colocan, es un cinturón o faja muy ceñida con la representación de Xoc. El lugar donde ocurrió el acto de vestir al dios es identificado como $u u k-h a '-n a l$, "casa de las siete aguas" (p. 892).

El tercer episodio es propiamente la "escena de la canoa", la cual reviste especial interés para este estudio. Utilizando imágenes de los vasos clasificados como K3033, K4358 y K731, Quenon y Le Fort señalan que las escenas de la canoa reflejan momentos de transición dentro de los eventos principales de la saga del Dios del Maíz. Es decir, como el renacimiento y la escena de vestir al dios transcurren en el mundo acuático subterráneo, su representación en una

\footnotetext{
40 Ibid., p. 885.

${ }^{41}$ Quenon y Le Fort (1997: 885).

42 "Visión Serpiente" le denomina Schele, citada por Quenon y Le Fort (1997: 886).
} 
canoa llevando un bulto (probablemente lleno de granos de maíz) atado al cuello sugiere la idea de que es trasladado al lugar donde resucitará. Existen además los huesos de la tumba 116 de Tikal, también con canoas llevando al dios, sólo que en este caso las canoas se hunden y señalan la muerte o sacrificio del dios en el mundo acuático subterráneo. El vaso identificado como K731 representa a diversos remeros: un remero-jaguar, un remero no identificado y un remero-chak, estos individuos portan diversos objetos que se creen relacionados con el ciclo de la agricultura del maíz y se dirigen hacia la tierra, representada por un caparazón de tortuga. El remero-chak lleva un arma de piedra cuatrilobulada, con la que rompe el caparazón y emerge de ella el Dios del Maíz. En otra escena citada, el dios está rodeado de chakob (los ayudantes de Chak) portando armas-rayo y rompiendo el caparazón de la tierra para que emerja-resucite el dios (pp. 892-894).

El cuarto episodio de la saga es la llamada escena de la resurrección del dios. Una vez que ha nacido en el submundo acuático, ha sido vestido y trasladado en la canoa, el dios emerge de un caparazón de tortuga, la cual es representada a veces con cabezas de ancianos a sus lados. El caparazón es roto, como ya se mencionó, por los chakob con hachas-rayo, y de allí surge el dios, lo cual es una representación simbólica del crecimiento de la planta de maíz (pp. 894-898). Según Quenon y Le Fort, lo anterior no sólo representa el crecimiento de la planta sino que también es un símbolo de la creación de la humanidad.

Podemos distinguir a partir de estos fragmentos, que la saga del Dios del Maíz inicia en una fecha predeterminada por los escribas mayas, cuando se realiza la creación. El primer acto es colocar tres piedras que representan el hogar del centro del universo, después se pone orden y se jerarquiza a los dioses, lo cual ocurre en un mundo acuático, que es el "cielo acostado". En este mundo, Hun Nal Yeh, el Dios del Maíz, luego de "renacer" del monstruo Xoc, es ayudado a vestirse por una joven mujer desnuda para ser trasladado, en una canoa, por dos remeros divinos al lugar de la creación, y lleva una bolsa con granos para ser sembrados en aquel lugar. Al plantar los granos y crecer la planta de maíz, el dios "resucita". Posteriormente, Hun Nal Yeh muere, lo cual se aprecia en los huesos de la tumba 116 de Tikal, en la que se hunde con los remeros en el mundo acuático, para volver a renacer de Xoc. En otro momento, para rehacer el universo y dejar de existir en el Ch'a Chan, "cielo acostado", Hun Nal Yeh erige en la región del norte una casa de ocho divisiones llamada Wakah Chan, "cielo elevado", que también es representado como árbol celeste, por ejemplo, en las "cruces" del conjunto arquitectónico occidental de Palenque. Las ocho divisiones las componen cuatro puntos cardinales y cuatro intercardinales; el plano conformado por los puntos intercardinales es denominado "el cielo del cocodrilo". ${ }^{43}$

\footnotetext{
${ }^{43}$ Freidel, Schele y Parker (1993: capítulo II).
} 


\section{El mito de la creación olmeca}

¿Cómo juzgamos lo que fue el mito olmeca de la creación y sus influencias culturales? Seguramente contuvo muchos de los elementos reproducidos en el mito maya, y desde luego debió relacionarse con la observación de eventos astronómicos y el intento de explicarlos. El mito olmeca sin duda empieza en una fecha mítica, en la que un "Dios Primordial", dios viejo y sabio, un artista, realiza la creación. A diferencia de los mayas que situaban el evento en la Vía Láctea, pienso que los olmecas consideraban como el primer acto del "Dios Primordial" la creación del plano terrestre, ${ }^{44}$ para lo cual construyó la montaña primigenia. Posteriormente debió crear a los otros dioses, seres perfectos como él que lo acompañarían en esta época primigenia, un mundo subterráneo, oscuro y sin luz. A fin de crear un mundo que contara con un cielo elevado y un sol, así como con la humanidad, el "Dios Primordial" se dirigió a la montaña original y allí sembró semillas de maíz, que al crecer crearon el plano celeste; además, por el acto de sembrar se transformó en "Dios del Maíz". Una vez creados los dos planos, invocó la lluvia en el plano celeste, y al caer sobre la montaña original formaron fuentes de agua y ríos, uniéndose ambos planos mediante la lluvia, interpretada como "cuerdas de agua". El último acto de la creación es el ordenamiento de los rumbos cardinales e intercardinales, para lo cual el "Dios Primordial", ya como "Dios del Maíz", se traslada a la región del norte y allí ordena cada conjunto de cuatro rumbos cardinales y cuatro intercardinales, cada uno de los cuales representaba un plano celeste, un cielo. Ordenado el mundo y nacidas las plantas de maíz, ${ }^{45}$ el "Dios Primordial", bajo sus dos advocaciones, se traslada por ambos cielos en canoas divinas. Estas canoas, por analogía, resultan ser caracterizaciones dé los dos planos, por lo cual puede deducirse que una canoa manufacturada en jade representa uno de los planos celestes.

Quizá uno de los primeros rituales relacionados con este mito olmeca de la creación lo encontramos en las ofrendas de esculturas de madera de Manatí. Es claro que los que ofrendaron tal cantidad de bustos, arcillas de colores, ofrendas de hachas de jade y pelotas de hule, consideraban al cerro que hoy conocemos como Cerro Manatí un lugar sagrado. ${ }^{46}$ Muy probablemente para los pobladores de las inmediaciones fue el lugar mismo de la creación. En un territorio literalmente inundado de ríos, lagunas y pantanos, un culto al agua parece chocante. Pero el agua que surge del Cerro Manatí es cristalina y probablemente representaba un tipo de agua sagrada, equiparada con la sangre humana. Además, en los restos recuperados de la escultura 17 aparecieron pequeños huesos y

\footnotetext{
${ }^{44}$ Este plano terrestre era el equivalente a lo que los mayas llamaban Ch'a Chan, "cielo acostado".

${ }^{45} \mathrm{El}$ maíz se ha considerado como un alter ego del hombre, por lo que puede verse como una metáfora de la creación de la humanidad; véase Thompson (1987).

${ }^{46}$ Arqueólogo Ponciano Ortiz, comunicación personal.
} 
cuerdas que partían de la escultura a esos huesos, con seguridad de humanos ${ }^{47}$ - esta peculiaridad recuerda las cuerdas que unen a los dioses en $\mathrm{Na}$ ho chan witz- ${ }^{48}$ De manera significativa, las esculturas en Manatí están colocadas en conjuntos de tres, con una especie de espadas de madera (io remos?) asociadas a hachas de jade, las cuales bien pueden ser los dioses participantes de la creación equipados con hachas que representan semillas de maíz; recordemos que Hun Nal Yeh fue trasladado por otros dos dioses al lugar de la creación y llevaba una bolsa precisamente de granos de maíz.

Las canoas de jade constituyen un documento que nos puede proporcionar información valiosa sobre la cosmogonía antigua de los olmecas. En este caso, he utilizado dos de las cuatro canoas de jade que conozco, pero habría que considerar la probable existencia de otras más en colecciones particulares, que con seguridad aportarían más elementos para comprender este viejo sistema de creencias, el cual cambió a lo largo de los siglos de existencia de los olmecas. Los planos celestes, los vehículos sagrados y los ideogramas son apenas una parte de esta cosmogonía.

Recapitulando, puede concluirse lo siguiente:

a) Existe un acto de creación por un Dios Primordial, Dios IV, cuya representación es un monstruo bicéfalo. Él "eleva el cielo", es decir, realiza la creación.

b) Después de "elevar el cielo", el Dios Primordial siembra maíz en el sitio de la creación, seguramente una montaña sagrada, con lo cual se transmuta en el Dios Maíz.

c) El Dios II, o del Maíz, completa la creación al sembrar semillas de maíz en el sitio de la creación. Su representación es similar a la del Dios IV, pero con una planta sobre su tajo.

d) El sitio de la creación está representado por el glifo "Piel de Cocodrilo".

e) El Dios Primordial y el Dios del Maíz presiden planos de la existencia diferentes, el primero el plano celestial y el segundo el plano terrestre.

f) Las canoas, por analogía, representan estos diferentes "cielos", y en su ordenamiento en rumbos este-oeste y norte-sur, ordenan el mundo en dimensiones cardinales e intercardinales, de forma cuatripartita doble, es decir, un mundo de ocho posiciones.

g) Muchas de las ofrendas y la iconografía olmeca reproduce diversos momentos de este mito, con fines distintivos de la ritualidad que existió en esa tradición civilizatoria.

h) Elementos de este mito pasan a la cultura maya clásica, que los actualiza y ordena de acuerdo con sus propios intereses, imprimiéndoles su sello característico.

${ }^{47}$ Eric Cach, informe técnico al CRV-INAH, 1992.

48 Freidel, Schele y Parker (1993: capítulos II y III). 


\section{BIBLIOGRAFÍA}

Ayala Falcón, Maricela

1983 "El origen de la escritura jeroglífica maya", Antropología e historia de los mixezoques y mayas (Homenaje a Frans Blom), pp. 175-221, L. Ochoa y T. Lee (eds.). México: UNAM.

1985 "Introducción a la cultura maya", Olmecas y mayas en Tabasco. Cinco acercamientos, pp. 13-48, L. Ochoa (coord.). Villahermosa: Gobierno del estado de Tabasco.

Barrera Vázquez, Alfredo

1995 Diccionario maya. México: Porrúa.

Bernal, Ignacio

1968 "Los olmecas metropolitanos", El mundo olmeca, pp. 13-38. México: Porrúa.

Cach Avendaño, Eric Orlando

1992 Temporada 1992 del Proyecto Manatí. Informe Técnico al CRV-INAH.

Castro-Leal, Marcia

1985 "La cultura olmeca en Tabasco", Olmecas y mayas en Tabasco. Cinco acercamientos, pp. 49-92, L. Ochoa (coord.). Villahermosa: Gobierno del estado de Tabasco.

Coe, Michael D.

1978 "La fotogrametría y la ecología de la civilización olmeca", Anuario Antropológico, 4: 659-679. Xalapa: Universidad Veracruzana, Facultad de Antropología.

1985 "The Olmec heartland: evolution of ideology", Regional Perspectives on the Olmec, pp. 68-84, R. Sharer y David C. Grove (eds.). Cambridge: Cambridge University Press.

1992 El desciframiento de los glifos mayas. México: FCE.

—

1980 In the Land of the Olmec. The Archaeology of San Lorenzo Tenochtitlan. Austin: University of Texas Press.

Covarrubias, Miguel

1946 "El arte olmeca o de La Venta", Cuadernos Americanos, año V, vol. XXVIII (4): 153-179. México: UNAM.

1961 Arte indígena de México y Centroamérica. México: UNAM. 
Drucker, Philip

1952 La Venta, Tabasco. A Study of Olmec Ceramics and Art. Smithsonian Institution, Bureau of American Ethnology, Bulletin 153. EUA: United States Government Printing Office.

- Richard A. Diehl y Minze Stuiver

1957 "Fechas de radiocarbono de La Venta", Boletín del CIAM, 4: 31-33. México: Centro de Investigaciones Antropológicas de México.

El libro de los Libros del Chilam Balam

1998 Versión de Alfredo Barrera Vázquez y Silvia Rendón. México: FCE.

Florescano, Enrique

1994 Memoria mexicana. México: FCE.

1999 Memoria indígena. México: Taurus.

Freidel, David, Linda Schele y Joy Parker

1993 Maya Cosmos. Three Thousand Years on the Shaman's Path. Nueva York: Quill William Morrow.

Graham, John A.

1990 "Escultura olmeca y maya sobre canto en Abaj Takalik: su desarrollo e importancia", Arqueología, 3. México: INAH.

Joralemon, Peter David

1976 "The Olmec dragon: A study in Pre-Columbian iconography", Origins of Religious Art and Iconography in Preclassic Mesoamerica, pp. 27-71, H. B. Nicholson (ed.). Los Angeles: UCLA, Latin American Center Publications.

Kelly, David H.

1976 Deciphering the Maya Script, pp. 231-239. Austin y Londres: University of Texas Press.

Landa, fray Diego de

1959 Relación de las cosas de Yucatán. México: Porrúa (Colección Biblioteca Porrúa).

López Austin, Alfredo

1984 Cuerpo humano e ideología, las concepciones de los antiguos nahuas. México: UNAM, IIA, 2 vols.

Los códices mayas

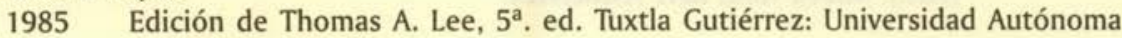
de Chiapas.

Lowe, Gareth W.

1985 "The heartland Olmec: Evolution of material culture", Regional Perspectives on the Olmec, pp. 33-67, R. Sharer y David C. Grove (eds.). Cambridge: Cambridge University Press. 
Lowe, Gareth W., Thomas A. Lee y Eduardo Martínez E.

1982 Izapa: An Introduction to the Ruins and Monuments. Provo: New World Archaeological Foundation, Brigham Young University.

Marcus, Joyce

1985 "Zapotec chiefdoms and the nature of formative religions", Regional Perspectives on the Olmec, pp. 148-197, R. Sharer y David C. Grove (eds.). Cambridge: Cambridge University Press.

Medellín Zenil, Alfonso

1983 Obras maestras del Museo de Xalapa. México: Studio Beatrice Trueblood.

Morley, Sylvanus G

1987 La civilización maya. México: FCE.

Ochiai, Kazuyasu

1985 Cuando los santos vienen marchando. Rituales públicos intercomunitarios tzotziles. San Cristóbal de Las Casas: Universidad Autónoma de Chiapas, Centro de Estudios Indígenas (Serie Monografías, 1).

Piña Chan, Román

1990 Los olmecas. La cultura madre. México: Lunwerg Editores (edición especial mexicana).

Pohorilenko, Antole

1972 "La pequeña escultura. El hombre y su experiencia artístico-religiosa”, El arte olmeca. Artes de México, 154: 35-37. México: Clío.

1990 "La estructura del sistema representacional olmeca”, Arqueología, 3: 85-90. México: INAH.

Popol Vuh. Antiguas historias de los indios quichés de Guatemala

1965 Advertencia, versión y vocabulario de Albertina Sarabia. México: Porrúa.

Proskouriakoff, Tatiana

1994 Historia maya. Compilación de Rosemary A. Joyce. México: Siglo XXI.

Quenon, Michel, y Genèvieve Le Fort

1997 "Rebirth and resurrection in Maize God iconography", The Maya Vase Book, a Corpus of Rollout Photographs of Maya Vases. pp. 884-992, Barbara y Justin Kerr (eds.). Nueva York: Kerr Associates.

Ruz Lhullier, Alberto

1992 El Templo de las Inscripciones. México: FCE.

Sharer, Robert, y David C. Grove (eds.)

1989 Regional Perspectives on the Olmec. Cambridge: Cambridge University Press. 
Schele, Linda, y David Freidel

1990 A Forest of Kings. The Untold Story of Ancient Mayas. Nueva York: Quill William Morrow.

Soustelle, Jacques

1998 Los olmecas. México: FCE.

Thompson, J. Eric S.

1971 Maya Hieroglyphic Writing. Oklahoma City: University of Oklahoma Press.

1987 Historia y religión de los mayas. México: Siglo XXI.

1992 A Catalog of Maya Hieroglyphs. Oklahoma City: University of Oklahoma Press.

Villa Rojas, Alfonso

1985 Estudios etnológicos. Los mayas. México: UNAM, IIA.

Weiant, C. W.

1943 An Introduction to the Ceramics of Tres Zapotes, Veracruz, Mexico. Smithsonian Institution, Bureau of American Ethnology Bulletin, 139. EUA: United States Government Printing Office.

Winfield Capitaine, Fernando

1988 La Estela 1 de La Mojarra, Veracruz, México. Museo de Antropología de Xalapa [fotocopia]. 